Метафорический концепт БИБЛИЯ как средство реализации эмотивности в немецких газетно-публицистических текстах на правовую тематику

\author{
Скотникова Т. А.
}

Аннотация. В статье рассматривается проблема достижения понимания в ходе коммуникации между специалистами и неспециалистами на примере немецкоязычных газетно-публицистических текстов на правовую тематику. Цель исследования - описать один из способов эмоционализации юридической лексики в немецкоязычных публицистических текстах на правовую тематику как средства популяризации предметно-специального языка права в общественно-политическом немецкоязычном дискурсе, способствующего эффективной правовой коммуникации. Научная новизна исследования заключается в использовании когнитивно-дискурсивного анализа метафор как средства реализации категории эмотивности на материале современного немецкого языка. В результате доказано, что для обеспечения правильного толкования правовых ситуаций авторы используют метафоры как средство эмоционализации содержания вопросов из области права, что способствует адекватному восприятию реципиентом текстов на узкоспециальные темы.

\title{
Metaphorical Concept of the BIBLE as a Means of Realising Emotiveness in German Newspaper-Publicistic Texts on Legal Topics
}

\author{
Skotnikova T. A.
}

\begin{abstract}
The article considers the problem of achieving understanding in the course of communication between specialists and non-specialists, using German-language newspaper-publicistic texts on legal topics as an example. The purpose of the study is to describe one of the ways of emotionalising legal vocabulary in German-language publicistic texts on legal topics as a means of popularising the subject-specific legal language in the socio-political German-language discourse, contributing to effective legal communication. Scientific novelty of the study lies in using a cognitive-discursive analysis of metaphors as a means of realising the category of emotiveness, involving the material of the modern German language. As a result, it has been proved that to ensure the correct interpretation of legal situations, authors use metaphors as a means of emotionalising the content of legal issues, which contributes to the recipient's adequate perception of texts on highly specialised topics.
\end{abstract}

\section{Введение}

Эмоции человека и механизмы их лингвистического обеспечения всегда были предметом научных изысканий, но особую актуальность эта проблема получила в связи с возвращением науки в русло антропоцентрической парадигмы. «Эмоции пронизывают жизнь человека, сопутствуют любой его деятельности, они важнейшая сторона человеческого существования. Без эмоций немыслим ни сам человек, ни его деятельность» (Бабенко, 1989, с. 3). Последние десятилетия отмечены ростом интереса лингвистов к изучению эмоций, о чем свидетельствуют многочисленные современные публикации на эту тему (Апресян, 1995; Бабенко, 1989; Буянова, Нечай, 2006; Вежбицкая, 1996; Мягкова, 1990; Маслова, 2007; Телия, 1991; Филимонова, 2007; Шаховский, 2008). Но, несмотря на пристальное внимание лингвистов к проблеме экспрессивности, она все же, как отмечает В. Н. Телия (1991), остается «одной из наиболее “размытых” областей исследования, которая в настоящее время распределяется между стилистикой, семантикой и прагматикой речи» (с. 7).

Современная наука считает, что эмоция всегда явно или скрыто сопутствует любому высказыванию и отражается в нем по-разному. Материалом исследования послужили статьи из авторитетного и часто цитируемого 
немецкого издания массовой коммуникации «Шпигель» (Der Spiegel) (Darnstädt, 2006; Darnstädt, Puhl, Zuber, 2009; Diehl, 2008; Russland durfte..., 2008; Smoltczyk, 2009), посвященные различным вопросам правового характера. Основное требование, предъявляемое к языку права, которым оперируют авторы статей подобного рода, заключается в доступности простому гражданину, не обладающему специальными знаниями в данной области и не владеющему правовой терминологией.

Для достижения указанной цели исследования необходимо решить следующие задачи:

- сформировать корпус метафор;

- произвести их систематизацию и классификацию;

- исследовать прагматический потенциал метафор.

Для установления эмотивных тем в статье применяются следующие методы исследования: целостнотекстовой и контекстуальный анализ. Необходимость рассмотрения функционально-стилистических особенностей текстовой эмотивности потребовала привлечения функционально-стилистического анализа.

Теоретической базой исследования, наряду с трудами В. Н. Телии (1991) и И. М. Кобозевой (2003), послужили публикации зарубежных авторов М. Шварц-Фризель (Schwarz-Friesel, 2007), Дж. Лакоффа и М. Джонсона (1990), в которых метафоры рассматриваются как определенная концептуальная конфигурация.

Практическая значимость исследования заключается в возможности использования результатов в процессе обучения немецкому языку как с лингвистической точки зрения, так и для глубокого ознакомления с особенностями предметно-специального права и ролью стилистических приемов создания эмотивного содержания в правовом дискурсе с помощью таких средств эмоционализации, как сравнения (Скотникова, 2018), прецедентные феномены (Скотникова, 2009), экспрессивный синтаксис и др.

\section{Основная часть}

Метафоры используются в статьях на международно-правовую тематику с целью «формирования определенного взгляда на мир сквозь призму образа, обычно имеющего некоторое эталонное значение для данного национально-культурного социума» (Телия, 1991, с. 31). Вслед за И. М. Кобозевой мы понимаем метафору как «образное построение, имеющее в качестве когнитивной основы уподобление объектов, относящихся к разным областям онтологии или типам» (Кобозева, 2003, с. 71). Как справедливо замечают Дж. Лакофф и М. Джонсон, концептуальная метафора является одной из примарных функций человеческого мышления: «...метафоры как языковые выражения становятся возможны только потому, что существуют в понятийной системе человека» (Лакофф, Джонсон, 1990, с. 390). Аналогичную точку зрения на природу метафоры выражает и В. Н. Телия, говоря о том, что «метафора есть универсально-лингвокреативное средство; это один из тропеических способов смыслопроизводства, закрепляемый посредством оязыковления концепта, протекающего как акт номинации» (Телия, 1991, с. 46-47). Образуя духовную репрезентацию, метафоры отображают определенную концептуальную конфигурацию и являются, по выражению М. Шварц-Фризель, «духовным мостом для человеческого разума, способствующим конструированию более высокой связи между входящими в концепт категориями» (Schwarz-Friesel, 2007, с. 200).

В исследуемых нами текстах наиболее активно используется концепт БИБЛИЯ, репрезентированный различными метафорами и метафорическими моделями:

1. метафора «война - ад, преисподняя»;

2. метафора «военные преступники - представители темных сил» (демоны, дьяволы, палачи и т.п.);

3. метафора «военное преступление - грехопадение»;

4. метафора «декларации о ликвидации всех форм расовой дискриминации - Библия».

В основе образования «концептуальной», сложной метафоры БИБЛИя «заложена идея моделирования как приема познания сложных сущностей, в том числе объектов, недоступных непосредственному наблюдению» (Кузьмина, 2007, с. 192). Проблемное поле правовых медиатекстов связано с тем, что принято называть трансцендентным опытом, который дискретен и не наблюдаем непосредственно. Поэтому авторы немецкоязычных публицистических текстов на правовую тематику наряду с библейским языком, способным выразить вневременной духовный смысл, используют метафорический язык.

Когнитивная база метафорического концепта БИБЛИЯ благодаря выразительности образной системы и глубокому нравственному содержанию апеллирует к библейскому сюжету как носителю ценностных представлений о добре и зле. Метафора как слой языка, наглядно отражающий историю духовной культуры, а также образ мышления народа, позволяет создателям текстов публицистического стиля на разные темы из правовой области жизни общества выполнить сложную задачу: с одной стороны, проинформировать читателей о важных событиях действительности, а с другой стороны, внушить свои мнения и оценки с помощью средств общеупотребительного языка (Костомаров, 2005, с. 121-122).

Как показало исследование, в оценке преступных действий военных агрессоров времен Второй мировой войны и вооруженных силовиков современности используются метафоры ада, темной, дьявольской силы. Фигуральность номинаций, употребляемых в таких примерах метафорического концепта БИБлИЯ, как ад, демон, грехопадение, представители темных сил, Библия, создает смысловое образование, в котором наблюдается противостояние темных сил свету, реализованное в противопоставлении двух полярных образов - ада и Библии, олицетворяющей Божие всемогущество, торжество светлых сил над тьмой. Создаваемый когнитивный диссонанс способствует реализации соответствующего эмоционально-оценочного отношения к объектам, входящим в данный метафорический концепт. 
В статье «Опасный люкс» („Ein gefährlicher Luxus“) (Darnstädt, Puhl, Zuber, 2009) сообщается о жестоком убийстве всех членов семьи жителя Уганды Калвина Окоры, совершенном детьми-солдатами, завербованными в боевую группировку во главе с военным преступником Йозефом Кони, злодеяния которого автор образно передает с помощью метафоры.

(1) Wäre es nicht so heiß gewesen und hätte der Baum nicht so angenehme Kühle gespendet, wäre Ocora mit seinen acht Zügen wohl schon wieder im Dorf gewesen, als das Inferno über Lucodi im Norden Ugandas hereinbrach. So aber schreckte Ocora aus dem Schlaf, als er ein Rascheln vernahm... er... rannte los - fort von den Rebellen, die gerade aus dem Busch traten, Jugendliche in Tarnanzügen, die auf den Pfiff ihres Anführers wahllos das Feuer aus Kalaschnikows eröffneten (Darnstädt, Puhl, Zuber, 2009). / Если бы не было так жарко и дерево не создавало приятную прохладу, Окора был бы уже в деревне вместе со своими восемью козами, как вдруг над Лукоди на севере Уганды разверзлась преисподняя. Окора, вздрогнув, проснулся, когда услышал шелест... он убежал прочь от боевиков, которые как раз выходили из-за кустов: молодые ребята в костюмах камуфляжного цвета, открывавшие по свистку главаря беспорядочный огонь из автоматов Калашникова (здесь и далее перевод выполнен автором статьи. - T. С.).

(2) Joseph Kony ist ein Teufel, der vorgibt, in Gottes Auftrag zu handeln. Er hat sich zurückgezogen in den Dschungel und sammelt neue Kindersoldaten um sich (Darnstädt, Puhl, Zuber, 2009). / Йозеф Кони - дьявол, действующий якобы по поручению Бога. Он скрылся в джунглях и собирает вокруг себя солдат детского возраста.

Следующий пример:

(3) Groß war die Furcht, die Dämonen könnten entgegen allen Berichten am Leben sein und während des Prozesses plötzlich auftauchen (Darnstädt, 2006). / Возникал большой страх, что демоны могли быть живыми вопреки всем сообщениям и могли появиться неожиданно во время процесса.

Под демонами в данном примере из статьи об историческом судебном процессе в Нюрнберге подразумеваются главные военные преступники из окружения Гитлера: Гиммлер и Геббельс, которые в ходе Нюрнбергского процесса не вошли в список обвиняемых, поскольку их смерть была установлена.

Перед военным трибуналом как военный преступник предстал промышленник и финансовый магнат Густав Крупп, на предприятиях которого в огромных масштабах производились танки, артиллерия и другое военное снаряжение. Однако по возрасту и состоянию здоровья он был освобожден от уголовной ответственности.

(4) Krupp, da war sich Jackson sicher, war der Vertreter der finstersten Mächte unter den deutschen Kriegstreibern (Darnstädt, 2006). / Крупп, по убеждению Джексона, был представителем темных сил среди немецких разжигателей войны.

В статье «Старик, процесс и смерть» („Der alte Mann, ein Prozess und der Tod“) (Diehl, 2008) речь идет об эсэсовце, который убил во время Второй мировой войны в оккупированных Нидерландах трех невинных людей. Лишь недавно было выдвинуто обвинение против этого 86-летнего обитателя дома престарелых.

(5) Die SS-Schergen, ausgestattet mit der Lizenz zum Morden, nutzten dabei nach Ansicht der Gerichte die Argund Wehrlosigkeit der überraschten und unbewaffneten Männer aus. Die Racheengel der Besatzer kamen, feuerten und verschwanden - kaltblutig, hinterlistig, tödlich (Diehl, 2008). / Палачи CC, наделенные лицензией на убийство, использовали, по мнению суда, наивность и беззащитность застигнутых врасплох и невооруженных мужчин. Ангелы мести оккупантов пришли, выстрелили и исчезли - хладнокровно, коварно, смертельно.

Преступления по захвату заложников, совершаемые сегодня вооруженными боевиками, расцениваются в соответствии с библейскими канонами как грех, грехопадение - выразительная область эксплицируемого контекста данной метафоры отображает негативное отношение автора к данным преступлениям нацистов.

Эти же образы используются в современных текстах, посвященных преступлениям и нарушениям прав человека в ходе военных действий по освобождению заложников.

(6) Es ist zwar international üblich geworden, eigene Staatsangehörige im Ausland auch durch begrenzte Militäraktionen zu schützen. Es gab für die Bundeswehr 1997 einen solchen Präzedenzfall bei der Befreiung deutscher Staatsangehöriger in Tirana, es gab international immer wieder auch andere solcher Sündenfälle, wo man Geiseln befreit und ausgeflogen hat. Diese waren aber immer lokal und auf den humanitären Zweck begrenzt (Russland durfte..., 2008). / Защита своих сограждан за границей путем осуществления небольших военных акций стала в мире обычной практикой. В 1997 году вооруженные силы ФРГ столкнулись с подобным прецедентом в ходе освобождения немецких граждан в Тиране. Другие случаи подобного грехопадения постоянно происходят в мире и сопровождаются освобождением заложников и их вывозом из страны на самолете. Но они имеют локальный характер и ограничиваются гуманитарной целью.

С другой стороны, для обозначения положительной оценки действий мирового сообщества, связанных с принятием на Всемирной конференции по борьбе против расизма Декларации о ликвидации всех форм расовой дискриминации, используется метафорическое отождествление этого документа со священной книгой.

(7) Wichtig ist ein sandfarbenes Paperback, auf das der Afroniederländer Iwan Leeuwin tippt: „Das ist unsere Bibel“, sagt er: „Deswegen sind wir hier“. Es ist „Erklärung und Aktionsprogramm“ der Weltkonferenz gegen Rassismus. Beschlossen am 8. September 2001 in Durban, Südafrika. Und schnell vergessen. <...> „Durban“ ist die Bibel der Blockfreien (Smoltczyk, 2009). / Важное значение имеет книга в мягком переплете песочного цвета, которой едва касаются пальцы голландца африканского происхождения Ивана Лиувина: «Это наша Библия», говорит он: «Поэтому мы здесь». Это «Декларация и программа действий» Всемирной конференции по борьбе с расизмом, принятая 8 сентября 2001 года в Дурбане в Южной Африке. И быстро забыта. <...> «Дурбан» это Библия для неприсоединившихся стран. 


\section{Заключение}

Таким образом, проведенное исследование позволяет сформулировать выводы о некоторых особенностях функционирования метафор и их роли в соблюдении требования доступности языка в текстах публицистики на правовую тематику. Предпринятый анализ метафорического концепта БИБЛИЯ в немецком правовом медиадискурсе подтверждает значительную роль использования различных видов эмотем для обеспечения доступности коммуникации между специалистами и неспециалистами. Использование метафор в немецком правовом медиадискурсе является одним из наиболее эффективных способов осуществления коммуникативного воздействия на адресата. Данная эффективность обусловлена заключенной в них системой ценностных представлений и моральных ориентиров, основанной на многовековом религиозном опыте народа, а также их компактностью и смысловой насыщенностью. Библейские концепты, универсалии христианского религиозного сознания в немецкоязычных публицистических текстах на правовую тематику играют роль своеобразного кода, важного для адекватной интерпретации поднимаемых юридических вопросов из области международного права; они обеспечивают понятность содержания узкоспециальных вопросов для простых граждан, неспециалистов в области права. Сложный метафоризм концепта БИБЛИЯ может стать ключом к пониманию и интерпретации немецкоязычных публицистических текстов на правовую тематику, которые, как правило, нелегко воспринимаются среднестатистическим читателем, не имеющим специальной подготовки в области права.

Перспективы дальнейшего исследования заключаются в изучении метафор и метафорических моделей других концептов, а также таких средств эмоционализации правового дискурса, как прецедентные феномены, экспрессивный синтаксис и другие стилистические приемы создания эмотивного содержания публицистических текстов.

\section{Источники | References}

1. Апресян Ю. Д. Избранные труды: в 2-х т. М.: Школа «Языки русской культуры», 1995. Т. II. Интегральное описание языка и системная лексикография.

2. Бабенко Л. Г. Лексические средства обозначения эмоций в русском языке. Свердловск: Изд-во Уральского ун-та, 1989.

3. Буянова Л. Ю., Нечай Ю. П. Эмотивность и эмоциогенность языка: механизмы экспликации и концептуализации: монография. Краснодар: Изд-во Кубанского гос. ун-та, 2006.

4. Вежбицкая А. Язык. Культура. Познание. М.: Русские словари, 1996.

5. Кобозева И. М. Интенциональный и когнитивный аспекты смысла высказывания. М.: Изд-во Московского ун-та, 2003.

6. Костомаров В. Г. Наш язык в действии: очерки современной русской стилистики. М.: Гардарики, 2005.

7. Кузьмина Н. А. Интертекст и его роль в процессах эволюции поэтического языка. М.: КомКнига, 2007.

8. Лакофф Дж., Джонсон М. Метафоры, которыми мы живем // Теория метафоры: сборник / пер. с англ., фр., нем., йен., польск. яз.; вступ. ст. и сост. Н. Д. Арутюновой; общ. ред. Н. Д. Арутюновой и М. А. Журинской. М.: Прогресс, 1990.

9. Маслова В. А. Ноmo lingualis в культуре: монография. М.: Гнозис, 2007.

10. Мягкова Е. Ю. Эмоциональная нагрузка слова. Воронеж: Изд-во Воронежского гос. ун-та, 1990.

11. Скотникова Т. А. Сравнения как средство реализации эмотивности немецких газетно-публицистических текстов на правовую тематику // Языковое бытие человека и этноса: сборник научных трудов по материалам XV Березинских чтений (г. Москва, 25 мая 2018 г.) / под ред. В. А. Пищальниковой, Л. Р. Комаловой, Н. Н. Германовой. М.: Институт научной информации по общественным наукам РАН, 2018.

12. Скотникова Т. А. Эмотивность немецких газетно-публицистических текстов на правовую тематику // Вестник Московского государственного лингвистического университета. 2009. Вып. 576.

13. Телия В. Н. Человеческий фактор в языке: языковые механизмы экспрессивности. М.: Наука, 1991.

14. Филимонова О. Е. Эмоциология текста. Анализ репрезентации эмоций в английском тексте: учебное пособие. СПб.: Книжный дом, 2007.

15. Шаховский В. И. Лингвистическая теория эмоций: монография. М.: Гнозис, 2008.

16. Darnstädt T. Das Weltgericht. 2006. URL: https://www.spiegel.de/politik/das-weltgericht-a-83fecbe5-0002-00010000-000049214563

17. Darnstädt T., Puhl J., Zuber H..,Ein gefährlicher Luxus“. 2009. URL: https://www.spiegel.de/politik/eingefaehrlicher-luxus-a-76f3b2c2-0002-0001-0000-000063546823

18. Diehl J. Der alte Mann, ein Prozess und der Tod. 2008. URL: https://www.spiegel.de/panorama/justiz/kriegsverbrechender-alte-mann-ein-prozess-und-der-tod-a-547739.html

19. „Russland durfte Südossetien zu Hilfe eilen“. 2008. URL: https://www.spiegel.de/politik/ausland/voelkerrechtrussland-durfte-suedossetien-zu-hilfe-eilen-a-571853.html

20. Schwarz-Friesel M. Sprache und Emotion. Tübingen - Basel: A. Francke Verlag, 2007.

21. Smoltczyk A..,Es muss schmerzen“. 2009. URL: https://www.spiegel.de/politik/es-muss-schmerzen-a-ad3d05360002-0001-0000-000065169772 


\section{Информация об авторах | Author information}

\section{RU Скотникова Татьяна Андреевна ${ }^{1}$}

${ }^{1}$ Московский государственный лингвистический университет

\section{EN Skotnikova Tatyana Andreewna ${ }^{1}$}

${ }^{1}$ Moscow State Linguistic University

${ }^{1}$ tati2137@mail.ru

\section{Информация о статье | About this article}

Дата поступления рукописи (received): 19.09.2021; опубликовано (published): 30.11.2021.

Ключевые слова (keywords): метафора; метафорический концепт; метафорическая модель; эмотема; metaphor; metaphorical concept; metaphorical model; emoteme. 